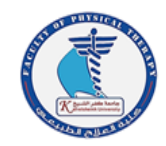

\title{
The application of total quality management standards in Egyptian physiotherapy colleges
}

\author{
Aliaa M Elabd \\ Department of Basic Science, Faculty of Physical Therapy, Pharos University in Alexandria, \\ Alexandria, Egypt.
}

\author{
Correspondence to \\ Aliaa M Elabd \\ Department of Basic \\ Science, Faculty of \\ Physical Therapy, Pharos \\ University in Alexandria, \\ Alexandria, Egypt. \\ Tel: 01069352446 \\ Email: \\ aliaelabd88@gmail.com
}

\begin{abstract}
:
Purpose: This study was conducted to identify the extent to which TQM standards applied to Egyptian physiotherapy colleges from the point of view of their administrative leadership, to determine whether there is difference depending on the type of faculty (government or private) and to determine the correlation between the number of experience years and the extent of TQM application.

Methods: The study sample consisted of 12 administrative leaders (deans and vice deans) from 7 faculties. The study tool was a questionnaire consisted of 55 items with established validity and reliability; the questionnaire was divided into 7 fields, reflecting the total quality standards in education. Statistical analysis was performed using the means and standard deviations of the areas of the questionnaire, independent sample t tests and using Pearson's correlation coefficient.

Results: although the overall average of the means of the scores was high, there is statistically significant difference between the means of the degree of application of TQM in the faculties of physiotherapy in favor of government colleges. Additionally, the results showed no correlation between the number of experience years of the study sample and the grades of their answers on the question axes.

Conclusion: it is highly recommended to implement comprehensive quality programs in education while paying special attention to private colleges.

Key words: Administrative Leadership; Faculties; Physical Therapy; Standards; Total Quality Management.
\end{abstract}

It is a coordinated organizational approach in pleasing both outside and inner clients by meeting their desires on ceaseless bases through getting everybody included with the organizational working on persistent enhancement of all items, administrations and strategies together with genuine problem solving methodology. It is an approach to progress the adequacy and adaptability of the organization as a whole, through total involvement of the employee in all perspectives, process and activities. (2)

In TQM is a wide management approach, not just a narrow quality control or quality assurance function. It ought to be recalled that everybody within the organization is included in TQM not just the project excellence. (1) 
manager. (3) Through these definitions, it is possible to determine the important characteristics and the critical offerings of TQM, such as: continuous advancement; involvement of individuals, capacities and functions; structured and systematic approach; quality control at each step of the operating process and at each organization level; development of human and organizational capabilities; proficient using of assets; individuals participation; client fulfillment; creating a quality culture and so on. (4)

Recent literature highlights a growing interest in applying TQM in education due to a wide variety of reasons. They include pressures from society for continuous development of academic standards with advancing technology; government schemes with funds allocation, that benchmarks research and education in the field of quality; expanding competition between different private and government academic institutions, and reduction in the funds for research and teaching. (5)

Bayraktar et al, suggested that a number of TQM elements have a very important role in process improvement including, "leadership", "vision", "measurement and evaluation", "process control and improvement", "program design", "quality system improvement", "employee involvement", "recognition and reward", "evaluation and training", "student focus", and other stakeholder focus" in higher education. (6)

The field of physiotherapy is one of the modern fields that have emerged to complement the medical system and meet the needs of patients and society. Physiotherapy is considered one of the most vital and important areas for its relevance to patients' health, quality of life and the extent to which they are fit to practice their daily activities. (7,8) Therefore, Egyptian officials have given great attention to the study of this field and many private and governmental physiotherapy colleges have been established at the republic level to prepare graduates capable of meeting the needs of the labor market. These colleges aim to prepare physiotherapists able to raise the efficiency of the medical service provided to the patients or work to improve the performance of athletes and prepare researchers in the field of physiotherapy able to keep pace with local and regional development. $(7,8)$

College management is one of the basic pillars to achieve its objectives. Its administrative leaders must be taken care of and attention as a link between subordinates and workers and field, and to raise their competencies to achieve the objectives of the educational process better. (9) Thus, this study was conducted to know the extent to which the quality management of the Egyptian physiotherapy faculties has been implemented from the point of view of its administrative leaders, to determine whether there is difference depending on the type of faculty (government or private) and to determine the correlation between the number of experience years and the extent of TQM application

\section{Methods}

An observational cross-sectional study was conducted. Participation was voluntary and informed assent was gotten from each member before inclusion in the study.

\subsection{Participants:}

A total of 7 Egyptian faculties of physical therapy were used as a sample for this study as follow:

2 governmental faculties (Cairo and south valley) which are considered the oldest and the newest governmental faculties in addition to 5 private faculties (October $6^{\text {th }}$, Pharos, Horus, El-Delta and Egyptian Chinese universities) which include among them the oldest and one of the newest private faculties. From the whole faculties, a total sample of 12 administrative leaders participated in the study (5 from governmental faculties and 7 from private faculties)

\section{2 .2.The study tool:}

A questionnaire was constructed to collect data from the study sample.

\subsubsection{Validity of the questionnaire}

It is an important requirement for the study tool, which is the ability to measure what is designed to measure it, and to know how appropriate the paragraphs are for the purpose for which it was prepared. In order to verify the validity of the tool and to verify its validity in terms of drafting, clarity and comprehensiveness, the researcher relied on logical validity, so the tool was presented to referees with experience and competence in the aspects of TCM and its dimensions, in order to provide data and information about the truthfulness of the content of this tool. According to opinions, observations and suggestions of the arbitrators, some amendments were made to correct, modify, and to rearrange some paragraphs.

The final questionnaire consists of 55 paragraphs divided into seven dimensions: strategic planning, administrative leadership, organizational structure, resources and potentials, scientific research, continuous improvement and community participation. The answers have been determined by a five point likert scale: strongly agree, agree, neither agree nor disagree, disagree and strongly disagree.

\subsubsection{Reliability of the tool:}

It is also one of the main requirements in the study tool, to give consistency in the results when applied multiple times, and to ensure the stability of the tool. The stability and internal consistency of the instrument as a whole and its areas were calculated 
using the Kronbach Alpha equation and the result was alpha $=0.0764$

\subsection{Measurement procedure:}

The study tool was constructed in both a paper form and an electronic form. The researcher distributed 9 paper questionnaires on the sample of the study participants who are easy to reach and interview them personally. After giving them the required time, 7 questionnaires were retrieved and approved for statistical analysis purposes. The electronic form questionnaires were sent to 8 people via email after telephone coordination with them. Only 5 replies were received and 3 responses were not received.

\subsection{Data analysis:}

Reported data were analyzed using Statistical Package for Social Sciences (SPSS) computer program (version 24) (Charles Flint, New York, USA) as follow:

- Alpha-Cronbach correlation coefficient of the study instrument was used to ensure its stability

- The arithmetical averages and standard deviations of the areas of the questionnaire were used to determine extent of TQM application in Egyptian physical therapy faculties.

- Independent sample t-test was used to determine whether there is a statistical significant difference between faculties depending on the faculty type either governmental or private; independent sample $\mathrm{t}$-tests were used to find the differences between the two groups for the average responses of the tool as a whole and for each axis of the questionnaire.

- Pearson's correlation coefficient was used to determine the correlation between the number of administrative leader experience years in his job and the extent of TQM application

\section{Results}

A total of 17 leaders from 10 faculties (7 leaders from 4 governmental faculties and 10 leaders from 8 private faculties) were invited to participate in the study using 9 paper questionnaires and 8 electronic questionnaires. 12 leaders (5 from 2 governmental faculties and 7 from 5 private ones) agreed to participate and their responses were retrieved. Figure 1 shows a flow diagram of participants' invitation and retention while Table 1 shows the details of the study sample. The results were promising, where the average responses of the sample were high in all the criteria. The averages and standard deviations calculated for the responses of the study sample to each of the study instrument areas revealed that the highest priority is the strategic planning where the average answers of the sample: 4.72 and that the lowest axis is the scientific research where the average answers of the sample: 4.12. (Table 2)

Table 1: The details of the study sample:

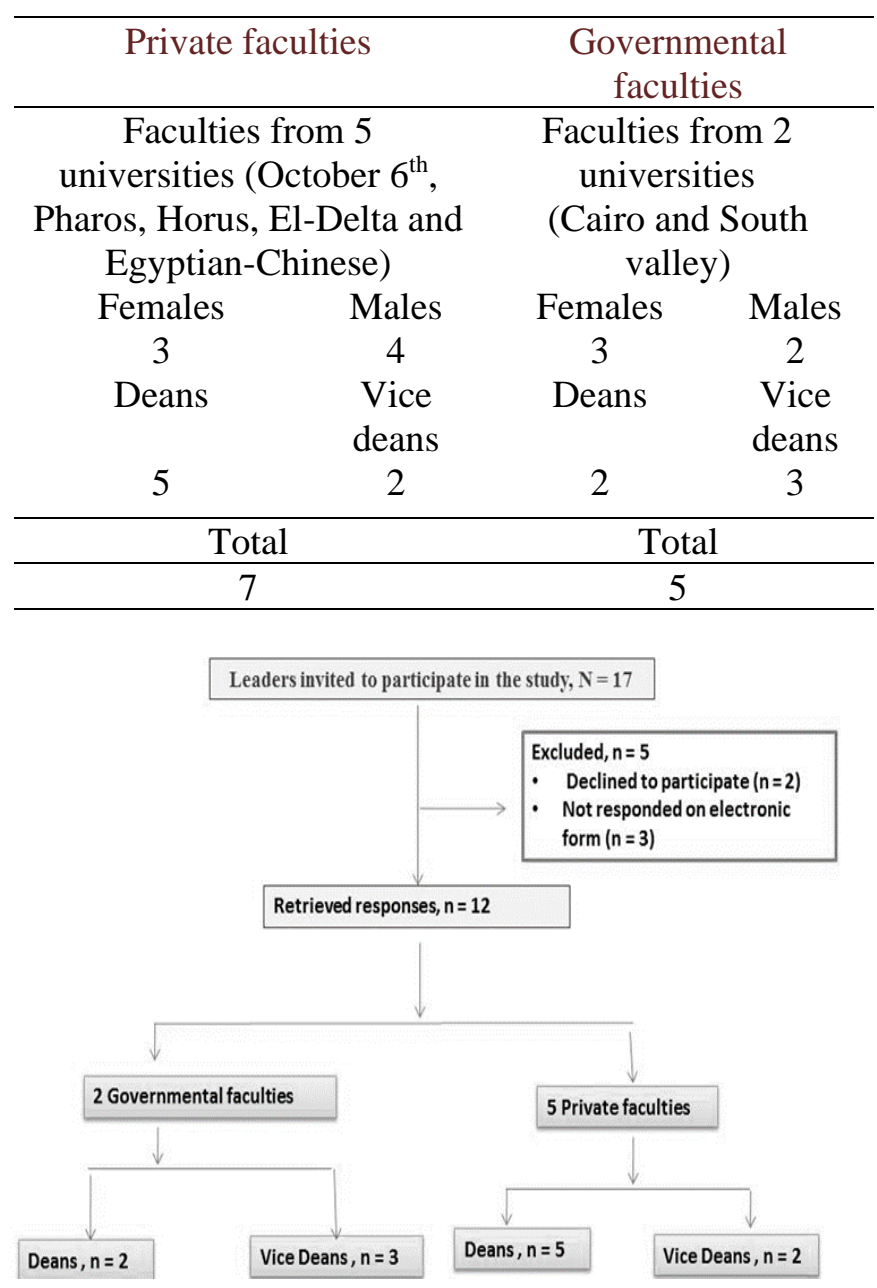

Figure 1: A flow diagram of leaders' invitation and retention

Table 2: The average responses of the sample

\begin{tabular}{|c|c|c|c|c|c|}
\hline Dimension & $\mathrm{N}$ & Min & $\operatorname{Max}$ & Mean & SD \\
\hline $\begin{array}{l}\text { Strategic } \\
\text { planning }\end{array}$ & 12 & 4.00 & 5.00 & 4.73 & 0.37 \\
\hline $\begin{array}{l}\text { Administrative } \\
\text { leadership }\end{array}$ & 12 & 3.88 & 4.75 & 4.44 & 0.323 \\
\hline $\begin{array}{l}\text { Organizational } \\
\text { Structure }\end{array}$ & 12 & 3.89 & 4.78 & 4.47 & 0.326 \\
\hline $\begin{array}{l}\text { Resources and } \\
\text { potentials }\end{array}$ & 12 & 3.5 & 5.00 & 4.45 & 0.548 \\
\hline $\begin{array}{l}\text { Scientific } \\
\text { research }\end{array}$ & 12 & 3.63 & 4.88 & 4.13 & 0.494 \\
\hline $\begin{array}{l}\text { continuous } \\
\text { improvement }\end{array}$ & 12 & 3.17 & 4.67 & 4.17 & 0.477 \\
\hline $\begin{array}{l}\text { Community } \\
\text { participation }\end{array}$ & 12 & 3.6 & 5.00 & 4.55 & 0.474 \\
\hline $\begin{array}{l}\text { Mean of the } \\
\text { total }\end{array}$ & 12 & 3.89 & 4.78 & 4.42 & 0.34 \\
\hline
\end{tabular}


Independent sample t-tests revealed that, the average participation dimension where there is a negative responses on the tool as a whole showed statistically correlation between its application and the number of the significant differences between responses in favor of leader experience years in his job. (Table 4)

government colleges if compared to their counterparts in private colleges. Specifically, the differences were statistically significant for strategic planning axes, organizational structure, resources and potentials, scientific research, continuous improvement ( $\mathrm{p}<0.05)$. Differences are not statistically significant for both administrative leadership and community service. (Table 3, Figure 2)

Table 3: Comparison between mean values of TQM application measured for governmental and private faculties:

\begin{tabular}{|c|c|c|c|c|c|c|}
\hline \multirow[t]{2}{*}{ Dimension } & \multicolumn{2}{|c|}{$\begin{array}{l}\text { Government } \\
\text { faculties }\end{array}$} & \multicolumn{2}{|c|}{$\begin{array}{l}\text { Private } \\
\text { faculties }\end{array}$} & \multirow[t]{2}{*}{$\mathrm{t}$} & \multirow[t]{2}{*}{$\mathrm{p}$} \\
\hline & mean & SD & mean & SD & & \\
\hline $\begin{array}{l}\text { Strategic } \\
\text { planning }\end{array}$ & 5.00 & 0.00 & 4.57 & .932 & 2.89 & .03 \\
\hline $\begin{array}{l}\text { Administrative } \\
\text { leadership }\end{array}$ & 4.47 & 0.19 & 4.44 & .394 & .189 & .85 \\
\hline $\begin{array}{l}\text { Organizational } \\
\text { Structure }\end{array}$ & 4.78 & 0.01 & 4.30 & .285 & 4.42 & .01 \\
\hline $\begin{array}{l}\text { Resources and } \\
\text { potentials }\end{array}$ & 4.92 & 0.17 & 4.19 & .513 & 3.44 & .01 \\
\hline $\begin{array}{l}\text { Scientific } \\
\text { research }\end{array}$ & 4.63 & 0.5 & 3.84 & .139 & .076 & .04 \\
\hline $\begin{array}{l}\text { continuous } \\
\text { improvement }\end{array}$ & 4.63 & .08 & 3.91 & .395 & 3.52 & .01 \\
\hline $\begin{array}{l}\text { Community } \\
\text { participation }\end{array}$ & 4.85 & 0.10 & 4.37 & .522 & 2.35 & .05 \\
\hline Total & 4.75 & 0.07 & 4.23 & .277 & 4.75 & .00 \\
\hline
\end{tabular}
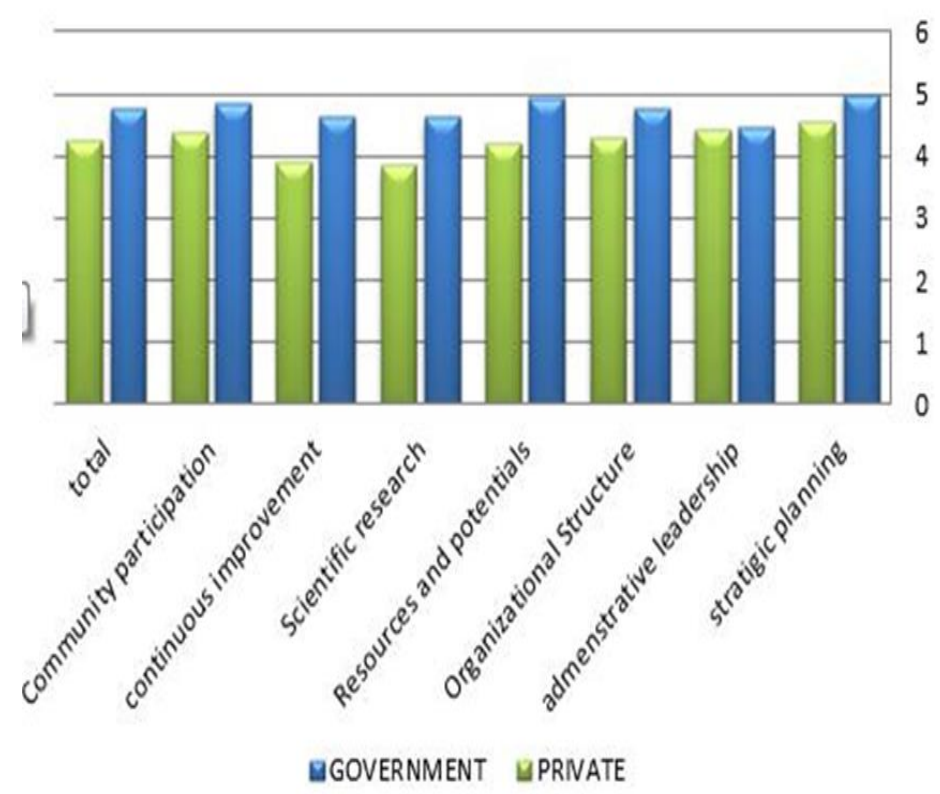

Figure 2: Application of TQM standards in government and private physical therapy colleges

The results of Pearson correlation showed that, there are no correlations $(\mathrm{p}>0.05)$ except for community
Table 4: Pearson correlation between the number of leaders experience years in their jobs and TQM application

\begin{tabular}{lcc}
\hline \multicolumn{1}{c}{ Dimensions } & \multicolumn{2}{c}{ Number of experience years } \\
\cline { 2 - 3 } & $\mathrm{P}$ & $\begin{array}{c}\text { Pearson } \\
\text { correlation }\end{array}$ \\
\hline $\begin{array}{l}\text { Strategic planning } \\
\text { Administrative }\end{array}$ & 0.44 & -.260 \\
$\begin{array}{l}\text { leadership } \\
\text { Organizational }\end{array}$ & .228 & -.396 \\
$\begin{array}{l}\text { Structure } \\
\text { Resources and } \\
\text { potentials }\end{array}$ & 0.720 & -.123 \\
$\begin{array}{l}\text { Scientific research } \\
\text { Continuous }\end{array}$ & 0.394 & -.135 \\
improvement & .877 & -.286 \\
$\begin{array}{l}\text { Community } \\
\text { participation }\end{array}$ & .99 & -.053 \\
Total & .532 & -.004 \\
\hline
\end{tabular}

\section{Discussion}

In this study, we aimed to determine the extent of TQM application in Egyptian faculties of physical therapy from their leaders' point of view and to investigate whether there is difference between governmental and private faculties. Finally we investigated the correlation between the number of leaders experience years in their current jobs and TQM application.

The results of the study were characterized by a degree of balance and objectivity. There was no extreme in the arithmetical averages of the application ratings, whether positive or negative, and the overall mean of the approval scores was high. Most of the responses of the study sample members can be viewed with satisfaction and optimism in the seriousness of the leaders in applying TQM standards and directing the resources and efforts to achieve quality and excellence through the use of educational techniques and modern educational innovations in educational situations.

For the second question, there are statistically significant differences depending on the faculty type either governmental or private, the results were surprising and showed the superiority of government colleges to the implementation of TQM standards. The relative novelty of private colleges and the lack of sufficient human resources and therefore lack of attention to the processes and attention is only to outputs, which is contrary to the standards of TQM. 
Finally, in relation to the last question concerning the correlation between the number of years of experience in the current job and the answers to the respondents, the results showed that there is no correlation, which is reassuring because it provides the opportunity for the transfer of authority and confirms that the application of TQM depends on the established system in the institution as a whole and its culture and not only in the directions and views of their current leaders because they are variables.

Recently, there is a growing interest in applying TQM in education, which encourages research in the field of quality. (10) Strategy should focus on the improvement of teaching system quality to fulfill the goals of TQM. TQM in education cannot be accomplished without everybody within the organization from bottom to top being involved to achieve the results, a passion for quality, and decisions based on achievement outcomes. (11)

According to Corrigam (1995) highlighted the importance of customer satisfaction for successful TQM. (12) A number of essential core values forming building blocks of proposed TQM system are administration, quality culture, nonstop improvement and advancement in educational process, employee involvement, and partnership development; both internally externally. (13)

For TQM to be successfully implemented in education, quality circles should be formed. A quality circle contains small groups of people who meet on a regular basis discussing problems to seek solutions and to cooperate with management in the application of those solutions. Quality circles use organized manners to problem solving; operate on the basis that employee involvement in decision making and problem solving improves the work quality. In education, quality deals with identification of the areas that affect the levels of teachings. (14)

TQM is a philosophy that demands on the improvement, enhancement, and change, of all the services provided to the students in education, the enhancement and change of each aspect of an organization or field. It acts to achieve efficiency to every aspect whether it is learning, teaching, curriculum or infrastructure. Leaders should examine the benefits of using a TQM program in their institutions. (15)

Toremen, et al. (2009) also suggested the requirement of an effective change in management, staff education and utilization of human resources to implement the principles of TQM. Quality improvement is a continual process that ought to be taken up from the operational level to senior administration. Primary schools affect upper level schools with their outcomes. Thus, TQM applications at primary schools are very important to achieve a high quality education system. This paper highlighted how to improve education quality at this basic level. (16)

TQM should incorporate leadership, cooperation, accountability without those dimensions; it cannot have any effect on the organization. Thus, these aspects of TQM should be implemented, improved for better functioning, performance and quality. (17)

\section{Limitations of the study:}

The study was limited to the administrators' points of view without reviewing staff members, employee and more importantly, students' points of view. Furthermore, the dependancy solely on the questionnaire as a measurement tool for TQM reduces the objectivity of the findings.

\section{Conclusion:}

As the results have been positive, they give promising and optimistic visions of the field of physical therapy in Egypt. Our results strongly suggest paying attention to the private and modern colleges and taking care of scientific research as a locomotive for advancement and consolidating the concept of culture change and development in society.

\section{Funding support:}

This research received no specific grant from any funding agency in the public, commercial, or medical for-profit sectors.

\section{Conflict of Interest:}

The Authors declare that there is no conflict of interest.

\section{References}

1. Sohel-Uz-Zaman, A S.Md, Anjalin, U. Implementing Total Quality Management in Education: Compatibility and Challenges. Open Journal of Social Sciences. 2016; 4: 207-217

2. Wani IA, Mehraj HK. Total Quality Management in Education: An Analysis. International Journal of Humanities and Social Science Invention. 2014; 3(6):71-78.

3. Thapa TB. Total Quality Management In Education. Academic Voices. 2011; 1(1): 80-89.

4. Sirvanci, M.B. Critical Issues for TQM Implementation in Higher Education. The TQM Magazine. 2004; 16: 382-386.

5. Talwar, M. S., Kumar T., Pradeep. Total Quality Management in Higher Education. University News. 2010; 48(1):12-14.

6. Bayraktar, E., Tatoglu, E. and Zaim, S. An Instrument for Measuring the Critical Factors of TQM in Turkish Higher Education. Total Quality Management and Business Excellence. 2008; 19: 551-574. 
7. Abichandani D, Vidhi Radia V. Awareness of Various Aspects of Physiotherapy among Medical Residents. International Journal of Science and Research. 2015;4(10): 1460-1465.

8. O'Donoghue G, Dean E. The physiotherapist's role in contemporary health care in Ireland: Responding to $21^{\text {st }}$ century indicators and priorities. Physiotherapy Practice and Research. 2010; 31(2):4-9.

9. McWhorter R, Delello J. Understanding the productivity of faculty members in higher education. International Journal of Management in Education 12(2): 154-160

10. Singh. Total Quality Management in Technical Education: A review New Frontiers in Education. 2008; 41(4): 392-396.

11. Weinstein L. The Application of a Total Quality Management Approach to Support Student Recruitment in School of Music. The journal of Higher Education Policy and Management. 2009; 34(4): 367-377.

12. Corrigan J. The Art of TQM. Quality Progress. 1995; 28:61-64.

13. Geddes L M. What TQM has to contribute to Change Management?. Journal of the Association for Communication Administration (JACA). 1995(2): 94 -101.

14. Karabulut A. Total quality management in education. Journal of standards. 2004; 513:4852.

15. Srivanci MB. Critical issues for TQM implementation in higher education. The TQM Magazine. 2004; 16(6):382-386.

16. Toremen, F. Total Quality Management practices in Turkish Primary schools. Quality Assurance in Education. 2009; 17(1):30 - 44.

17. Mannivannan M, Premila KS. Application of Principles of Total Quality Management (TQM) in Teacher Education Institutions. Journal of College Teaching and Learning. 2009; 6(6):7788 . 